\title{
IS THERE A COMMON ALPHA-EFFICIENCY IN POLYMINERAL SAMPLES MEASURED BY VARIOUS INFRARED STIMULATED LUMINESCENCE PROTOCOLS?
}

\author{
CHRISTOPH SCHMIDT ${ }^{1}$, JANINA BÖSKEN ${ }^{2,3}$ and THOMAS KOLB ${ }^{1}$ \\ ${ }^{I}$ Chair of Geomorphology \& BayCEER, University of Bayreuth, 95440 Bayreuth, Germany \\ ${ }^{2}$ Department of Geography, RWTH Aachen University, Templergraben 55, 52056 Aachen, Germany \\ ${ }^{3}$ Institute of Geography, University of Cologne, Albertus-Magnus-Platz, 50923 Cologne, Germany
}

Received 11 August 2017

Accepted 7 June 2018

\begin{abstract}
Dating of polymineral silt-sized samples by use of post-infrared infrared stimulated luminescence (pIRIR) protocols at elevated temperature has recently gained attraction due to assumed lower rates of anomalous fading. The $\alpha$-efficiency (or $a$-value) associated with the pIRIR signals as an integral part of age calculation has, however, not yet been sufficiently constrained. Here we present a set of $65 a$-values determined for 47 samples collected across Europe with two different IRSL protocols in two laboratories. By testing the basic preconditions for application of the single-aliquot regeneration (SAR) procedure to constrain $a$-values and by comparing SAR results to $a$-values obtained by multiple-aliquot protocols, we demonstrate that SAR-derived $a$-values are reliable for the majority of samples. While aliquot size and signal resetting mode prior to $\alpha$-regeneration do not appear to affect the resulting $a$-value, we detected significant differences in mean $a$-values measured in the two laboratories. For the pIRIR 290 signal, $a$-values average to $0.085 \pm 0.010$ (Bayreuth) and $0.101 \pm 0.014$ (Cologne), while a modified SAR protocol yields $0.081 \pm 0.008$ (Bayreuth). Whereas provenance-specific differences in $a$-values might be masked by overall scatter, systematic offsets between laboratories are attributed to technical issues such as heater and source calibration. Based on the present data set, use of the same routine dating equipment is strongly advised for both dose and $a$ value measurements.
\end{abstract}

Keywords: luminescence, infrared stimulated luminescence - IRSL, polymineral samples, alphaefficiency, $a$-value, loess.

\section{INTRODUCTION}

Measuring the infrared stimulated luminescence (IRSL) of K-feldspar or polymineral separates at elevated temperatures $\left(>150^{\circ} \mathrm{C}\right)$ after initial IRSL stimulation at $50^{\circ} \mathrm{C}\left(\mathrm{IRSL}_{50}\right)$ has gained considerable popularity for estimating the equivalent dose $\left(D_{\mathrm{e}}\right)$ in retrospective do-

Corresponding author: C. Schmidt

e-mail: christoph.schmidt@uni-bayreuth.de simetry (e.g., Thomsen et al., 2008; Thiel et al., 2011; Reimann and Tsukamoto, 2012). This technique - usually referred to as post-IR IRSL or pIRIR - offers access to feldspar-derived luminescence signals less affected by socalled anomalous fading (Wintle, 1973). The conceptual model explaining these lower fading rates builds upon an increased distance between trapping and recombination sites as stimulation temperature is raised, resulting in a decreased probability of tunneling recombination of opposite charge carriers (e.g., Jain and Ankjærgaard, 2011; Buylaert et al., 2012). There is however a trade-off between low fading rates of pIRIR signals and signal 
bleachability, i.e., the pIRIR stimulation temperature is inversely related to the optical resetting rate of the respective signal, while part of the signal remains unaffected by sunlight exposure ( $\mathrm{Li}$ and $\mathrm{Li}, 2011)$. This unbleachable residual has occasionally been determined in the laboratory by applying some sort of residual subtraction method in order to isolate the optically sensitive component from the bulk signal (e.g., Schatz et al., 2012; Li et al., 2013).

Commonly, either sand-sized $(\sim 90-250 \mu \mathrm{m})$ K-feldspar or silt-sized $(\sim 4-11 \mu \mathrm{m})$ polymineral grains are prepared for pIRIR measurements. While it is debatable whether the coarse grain size fraction should be HFetched to remove the outer layer influenced by external $\alpha$ radiation (e.g., Duller, 1992; Li and Li, 2011; Trauerstein et al., 2014; Kenzler et al., 2015), the $\alpha$-dose rate has to be fully considered for fine grains $(\sim 4-11 \mu \mathrm{m})$. To account for the different efficiency in producing luminescence of heavy particles such as $\alpha$-particles and slightly ionising radiation such as $\beta$ - and $\gamma$-radiation, the so-called $\alpha$-efficiency must be incorporated when calculating the dose rate (Aitken, 1985a). Among the different systems presented for quantifying $\alpha$-efficiency (see Aitken, $1985 b$, for a summary), the $a$-value system has most widely been used both for quartz and feldspar. This system is based on the findings of Aitken and Bowman (1975) indicating that the induced luminescence per unit of generated $\alpha$-track length (in $\mu \mathrm{m} \mu \mathrm{m}^{-3}=\mu \mathrm{m}^{-2}$ ) is nearly independent from the $\alpha$-particle's energy. Hence, the luminescence recorded after generating a certain cumulative length of $\alpha$-tracks is compared with the luminescence resulting from a known $\beta$-dose to calculate the $a$-value. In the case of quartz and mono-energetic $3.7 \mathrm{MeV}$ $\alpha$-particles (as delivered by many ${ }^{214} \mathrm{Am}$ sources), the $a$-value is by definition equal to the $k$-value, where the ratio of luminescence induced by an $\alpha$-dose (in Gy) to that induced by a $\beta$-dose (in Gy) is calculated. For nonquartz materials, a correction factor $r$ relates the materialspecific $a$-value to the quartz $a$-value (Aitken, 1985b). This correction factor largely depends on the density of the used material. Since the density of feldspar, however, only deviates $2 \%$ from the density of quartz, we used uncorrected $a$-values in this study.

Compared to the vast body of literature published during the past years on the application of the pIRIR protocol to various sedimentary archives, only relatively few studies determined the $a$-value individually for the samples investigated. Many authors refer to Rees-Jones (1995) when using an $a$-value of $0.08 \pm 0.02$, although this value is based on three samples only and - more importantly - determined for the IRSL signal recorded using a multiple-aliquot protocol and under strongly varying preheat and measurement conditions than the ones used in the respective studies (e.g., Stevens et al., 2011; Thiel et al., 2011; Buylaert et al., 2012; Vasiliniuc et al., 2012; Schmidt et al., 2014). Only Biswas et al. (2013) reported measured pIRIR $290 a$-values ranging from $0.036 \pm 0.003$ to $0.055 \pm 0.002$ for volcanic ash samples, determined by administering a known $\alpha$-dose to a bleached sample and recovering the equivalent $\beta$-dose using a single-aliquot regenerative dose protocol. These values are on average higher than the IRSL 50 -values of these samples by a factor of $1.28 \pm 0.03$ (Biswas et al., 2013). Successful dose recovery using either solely $\alpha$ regeneration or solely $\beta$-regeneration always combined with a fixed $\beta$-test dose for normalisation led the authors to conclude that this approach of $a$-value determination is accurate. In a more comprehensive study, Kreutzer et al. (2014) determined pIRIR $225 a$-values for five loess samples (polymineral fine grains) from Saxony (Germany), revealing a systematic difference between IRSL $_{50}$ and pIRIR $_{225} a$-values. Furthermore, the mode of signal resetting (heating vs. bleaching) prior to $\alpha$-irradiation appears to affect the size of the $a$-value (Kreutzer et al., 2014). Considering the results obtained in the referenced studies above, one might suspect that the pIRIR $a$-value of polymineral fine grains correlates positively with the pIRIR stimulation temperature. It therefore appears timely to further investigate the $a$-value of the pIRIR 290 signal for a range of different samples. Specifically, the present study aims at:

1) identifying a suitable method to accurately determine pIRIR $a$-values,

2) investigating whether there is a common pIRIR 290 $a$-value, independent of sample mineralogy or provenance, and

3) clarifying whether the pIRIR $290 a$-value is different from the $\mathrm{pIRIR}_{225} a$-value.

Many samples in our laboratories were recently measured with a distinct IRSL protocol (following the approach described in detail in Faust et al., 2015) which includes a high-temperature preheat and a $20 \mathrm{~min}$ pause prior to IRSL measurement, in order to minimise anomalous fading. In addition to pIRIR $290 a$-values, we therefore also report on the $a$-values determined with this procedure (termed $\mathrm{IRSL}_{\mathrm{F}}$ henceforth) in order to assess the variability of the $a$-value as a function of the IRSL/pIRIR measurement protocol. Details on both protocols employed in this study are given below.

\section{SAMPLES AND SAMPLE PREPARATION}

To evaluate both the variability of the pIRIR 290 $a$-value between samples of different mineralogy and geographical origin and within a set of samples originating from the same outcrop, we studied a total of 47 polymineral fine grain samples from 10 different locations in Europe. Table 1 provides a summary of these samples.

Prior to measurement, samples were dry or wet sieved to grain sizes $<63 \mu \mathrm{m}$, soaked in $10 \% \mathrm{HCl}$ and $10 \% \mathrm{H}_{2} \mathrm{O}_{2}$ to dissolve carbonates and oxidise organic matter, respectively, treated with $0.01 \mathrm{~N}$ sodium oxalate to disperse aggregates (only Cologne laboratory) and subsequently settled in a water column for distinct periods to extract the target grain size range of $\sim 4-11 \mu \mathrm{m}$ (application of 
Table 1. Summary of investigated samples. Sample codes BT... refer to the luminescence laboratory in Bayreuth, codes $C$-L... to the laboratory in Cologne; pIRIR ${ }_{290}=$ post-IR IRSL protocol with $290^{\circ} \mathrm{C}$ stimulation temperature (following Thiel et al., 2011); IRSLF $=I R S L$ protocol according to Faust et al. (2015); MAAD = multiple-aliquot additive-dose protocol applied both to the pIRIR 290 and the IRSLF emission (see main text for further details).

\begin{tabular}{|c|c|c|c|c|c|}
\hline $\begin{array}{l}\text { Sample } \\
\text { code }\end{array}$ & Provenance & Coordinates & Depositional environment & Applied protocols & sReference \\
\hline BT1257 & Titel, Serbia & $45^{\circ} 17^{\prime} 42^{\prime \prime} \mathrm{N}, 20^{\circ} 11^{\prime} 22^{\prime \prime} \mathrm{E}$ & Loess & pIRIR 290 & - \\
\hline$\overline{B T 1258}$ & Titel, Serbia & $45^{\circ} 17^{\prime} 42^{\prime \prime} \mathrm{N}, 20^{\circ} 11^{\prime} 22^{\prime \prime} \mathrm{E}$ & Loess & pIRIR 290 & 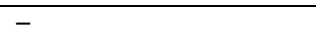 \\
\hline BT1259 & Titel, Serbia & $45^{\circ} 17^{\prime} 42^{\prime \prime} \mathrm{N}, 20^{\circ} 11^{\prime} 22^{\prime \prime} \mathrm{E}$ & Loess & pIRIR 290 & - \\
\hline$\overline{B T 1337}$ & Encantado I, Fuerteventura & $28^{\circ} 38^{\prime} 20^{\prime \prime} \mathrm{N}, 13^{\circ} 58^{\prime} 37^{\prime \prime} \mathrm{W}$ & Aeolian deposits & IRSLF & - \\
\hline BT1339 & Encantado I, Fuerteventura & $28^{\circ} 38^{\prime} 18^{\prime \prime} \mathrm{N}, 13^{\circ} 58^{\prime} 40^{\prime \prime} \mathrm{W}$ & Aeolian deposits & IRSLF & - \\
\hline BT1340 & Melian, Fuerteventura & $28^{\circ} 40^{\prime} 18^{\prime \prime} \mathrm{N}, 13^{\circ} 57^{\prime} 08^{\prime \prime} \mathrm{W}$ & Aeolian deposits & IRSLF & Roettig et al. (2017) \\
\hline BT1341 & Melian, Fuerteventura & $28^{\circ} 40^{\prime} 18^{\prime \prime N}, 13^{\circ} 57^{\prime} 08^{\prime \prime} \mathrm{W}$ & Aeolian deposits & IRSLF & Roettig et al. (2017) \\
\hline$\overline{B T 1342}$ & Melian, Fuerteventura & $28^{\circ} 40^{\prime} 09^{\prime \prime} \mathrm{N}, 13^{\circ} 57^{\prime} 14^{\prime \prime} \mathrm{W}$ & Aeolian deposits & IRSLF & Roettig et al. (2017) \\
\hline BT1343 & Melian, Fuerteventura & $28^{\circ} 40^{\prime} 09^{\prime \prime} \mathrm{N}, 13^{\circ} 57^{\prime} 14^{\prime \prime} \mathrm{W}$ & Aeolian deposits & IRSLF & Roettig et al. (2017) \\
\hline BT1344 & Melian, Fuerteventura & $28^{\circ} 40^{\prime} 22^{\prime \prime N}, 13^{\circ} 57^{\prime} 12^{\prime \prime W}$ & Aeolian deposits & $\begin{array}{l}\text { MAAD } \\
\left(\mathrm{pIRIR}_{290,}, \mathrm{IRSL}\right)\end{array}$ & Roettig et al. (2017) \\
\hline BT1345 & Melian, Fuerteventura & $28^{\circ} 40^{\prime} 22^{\prime \prime N}, 13^{\circ} 57^{\prime} 12 " \mathrm{~W}$ & Aeolian deposits & $\begin{array}{l}\text { MAAD } \\
\text { (pIRIR290, IRSLF) }\end{array}$ & Roettig et al. (2017) \\
\hline BT1421 & Encantado III, Fuerteventura & $28^{\circ} 38^{\prime} 21^{\prime \prime N}, 13^{\circ} 58^{\prime} 44^{\prime \prime} \mathrm{W}$ & Aeolian deposits & IRSLF & Roettig et al. (2017) \\
\hline$\overline{\text { BT1423 }}$ & Encantado III, Fuerteventura & $28^{\circ} 38^{\prime} 21^{\prime \prime N}, 13^{\circ} 58^{\prime} 44^{\prime \prime} \mathrm{W}$ & Aeolian deposits & IRSLF & Roettig et al. (2017) \\
\hline BT1424 & Encantado III, Fuerteventura & $28^{\circ} 38^{\prime} 21^{\prime \prime} \mathrm{N}, 13^{\circ} 58^{\prime} 44^{\prime \prime} \mathrm{W}$ & Aeolian deposits & IRSLF & Roettig et al. (2017) \\
\hline$\overline{\text { BT1425 }}$ & Encantado III, Fuerteventura & $28^{\circ} 38^{\prime} 21^{\prime \prime N}, 13^{\circ} 58^{\prime} 44^{\prime \prime} \mathrm{W}$ & Aeolian deposits & IRSLF & Roettig et al. (2017) \\
\hline BT1426 & Encantado III, Fuerteventura & $28^{\circ} 38^{\prime} 21^{\prime \prime N}, 13^{\circ} 58^{\prime} 44^{\prime \prime} \mathrm{W}$ & Aeolian deposits & IRSLF & Roettig et al. (2017) \\
\hline$\overline{\text { BT1432 }}$ & Enamorados, Fuerteventura & $28^{\circ} 38^{\prime} 05^{\prime \prime} \mathrm{N}, 13^{\circ} 59^{\prime} 06^{\prime \prime} \mathrm{W}$ & Aeolian deposits & IRSLF & - \\
\hline$\overline{\text { BT1513 }}$ & Jable 1, Fuerteventura & $28^{\circ} 38^{\prime} 38^{\prime \prime} \mathrm{N}, 13^{\circ} 58^{\prime} 28^{\prime \prime} \mathrm{W}$ & Aeolian deposits & $\mathrm{plRIR}_{290,}, \mathrm{IRSLF}$ & - \\
\hline$\overline{\text { BT1514 }}$ & Jable 1, Fuerteventura & $28^{\circ} 38^{\prime} 38^{\prime \prime} \mathrm{N}, 13^{\circ} 58^{\prime} 28^{\prime \prime} \mathrm{W}$ & Aeolian deposits & IRSLF & Roettig et al. (2017) \\
\hline BT1515 & Jable 1, Fuerteventura & $28^{\circ} 38^{\prime} 38^{\prime \prime N} \mathrm{~N}, 13^{\circ} 58^{\prime} 28^{\prime \prime} \mathrm{W}$ & Aeolian deposits & pIRIR290, IRSLF & Roettig et al. (2017) \\
\hline$\overline{\text { BT1517 }}$ & Jable 1, Fuerteventura & $28^{\circ} 38^{\prime} 38^{\prime \prime} \mathrm{N}, 13^{\circ} 58^{\prime} 28^{\prime \prime} \mathrm{W}$ & Aeolian deposits & $\mathrm{plRIR}_{290,}, \mathrm{IRSLF}$ & - \\
\hline$\overline{\text { BT1519 }}$ & Fuerteventura, Spain & $28^{\circ} 39^{\prime} 09^{\prime \prime} \mathrm{N}, 13^{\circ} 57^{\prime} 27^{\prime \prime} \mathrm{W}$ & Aeolian deposits & pIRIR $290, I_{R S L}$ & 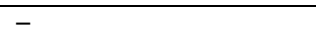 \\
\hline$\overline{B T 1525}$ & Jable 2, Fuerteventura & $28^{\circ} 38^{\prime} 50^{\prime \prime} \mathrm{N}, 13^{\circ} 58^{\prime} 38^{\prime \prime} \mathrm{W}$ & Aeolian deposits & pIRIR 290, IRSLF & Roettig et al. (2017) \\
\hline BT1528 & Jable 2, Fuerteventura & $28^{\circ} 38^{\prime} 50^{\prime \prime N}, 13^{\circ} 58^{\prime} 38^{\prime \prime} \mathrm{W}$ & Aeolian deposits & pIRIR290, IRSLF & - \\
\hline$\overline{\text { BT1529 }}$ & Montana Roja, Fuerteventura & $28^{\circ} 38^{\prime} 59^{\prime \prime} \mathrm{N}, 13^{\circ} 51^{\prime} 08^{\prime \prime} \mathrm{W}$ & Aeolian deposits & IRSLF & 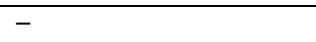 \\
\hline$\overline{\text { BT1401 }}$ & Eifel, Germany & $50^{\circ} 04^{\prime} 39^{\prime \prime} \mathrm{N}, 07^{\circ} 01^{\prime} 43^{\prime \prime} \mathrm{E}$ & Quartzitic slate & $\mathrm{pIRIR}_{290}$ & Schmidt et al. (2017) \\
\hline$\overline{\text { BT1415 }}$ & Vârghis, Romania & $46^{\circ} 12^{\prime} 58^{\prime \prime} \mathrm{N}, 25^{\circ} 32^{\prime} 36^{\prime \prime} \mathrm{E}$ & Aeolian cave deposit & $\mathrm{pIRIR}_{290}$ & Veres et al. (2018) \\
\hline$\overline{\text { BT1416 }}$ & Vârghis, Romania & $46^{\circ} 12^{\prime} 58^{\prime \prime N}, 25^{\circ} 32^{\prime} 36^{\prime \prime} \mathrm{E}$ & Aeolian cave deposit & pIRIR 290 & Veres et al. (2018) \\
\hline$\overline{\text { BT1417 }}$ & Întorsura Buzăului, Romania & $45^{\circ} 43^{\prime} 02^{\prime \prime} \mathrm{N}, 26^{\circ} 04^{\prime} 13^{\prime \prime} \mathrm{E}$ & Loamy hillslope deposit & $\mathrm{pIRIR}_{290}$ & 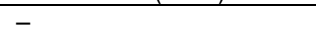 \\
\hline C-L3704 & Urluia, Romania & $44^{\circ} 05^{\prime} 42^{\prime \prime} \mathrm{N}, 27^{\circ} 54^{\prime} 07^{\prime \prime} \mathrm{E}$ & Loess & pIRIR 290 & - \\
\hline$\overline{C-L 3707}$ & Urluia, Romania & $44^{\circ} 05^{\prime} 42^{\prime \prime} \mathrm{N}, 27^{\circ} 54^{\prime} 07^{\prime \prime} \mathrm{E}$ & Loess & $\mathrm{pIRIR}_{290}$ & Obreht et al. (2017) \\
\hline C-L3778 & Stalać, Serbia & $43^{\circ} 40^{\prime} 39^{\prime \prime} \mathrm{N}, 21^{\circ} 25^{\prime} 04^{\prime \prime} \mathrm{E}$ & Loess & pIRIR 290 & Bösken et al. (2017) \\
\hline C-L3780 & Stalać, Serbia & $43^{\circ} 40^{\prime} 39^{\prime \prime} \mathrm{N}, 21^{\circ} 25^{\prime} 04^{\prime \prime} \mathrm{E}$ & Loess & $\mathrm{pIRIR}_{290}$ & Bösken et al. (2017) \\
\hline C-L3784 & Stalać, Serbia & $43^{\circ} 40^{\prime} 39^{\prime \prime} \mathrm{N}, 21^{\circ} 25^{\prime} 04^{\prime \prime} \mathrm{E}$ & Loess & pIRIR 290 & Bösken et al. (2017) \\
\hline$\overline{C-L 3786}$ & Stalać, Serbia & $43^{\circ} 40^{\prime} 39^{\prime \prime} \mathrm{N}, 21^{\circ} 25^{\prime} 04^{\prime \prime} \mathrm{E}$ & Loess & $\mathrm{pIRIR}_{290}$ & Bösken et al. (2017) \\
\hline C-L3787 & Stalać, Serbia & $43^{\circ} 40^{\prime} 39^{\prime \prime N}, 21^{\circ} 25^{\prime} 04^{\prime \prime E}$ & $\begin{array}{l}\text { Pedogenetically overprinted } \\
\text { loess }\end{array}$ & $\mathrm{pIRIR} 290$ & Bösken et al. (2017) \\
\hline$\overline{C-L 3788}$ & Stalać, Serbia & $43^{\circ} 40^{\prime} 39^{\prime \prime} \mathrm{N}, 21^{\circ} 25^{\prime} 04^{\prime \prime} \mathrm{E}$ & Loess & $\mathrm{pIRIR} 290$ & Bösken et al. (2017) \\
\hline C-L4029 & Vrsac, Serbia & $45^{\circ} 09^{\prime} 10^{\prime \prime} \mathrm{N}, 21^{\circ} 09^{\prime} 30^{\prime \prime} \mathrm{E}$ & Lacustrine sediment & pIRIR 290 & Zeeden et al. (in prep.) \\
\hline$\overline{C-L 4030}$ & Vrsac, Serbia & $45^{\circ} 09^{\prime} 10^{\prime \prime} \mathrm{N}, 21^{\circ} 09^{\prime} 30^{\prime \prime} \mathrm{E}$ & Lacustrine sediment & $\mathrm{pIRIR}_{290}$ & Zeeden et al. (in prep.) \\
\hline C-L4031 & Vrsac, Serbia & $45^{\circ} 09^{\prime} 10^{\prime \prime} \mathrm{N}, 21^{\circ} 09^{\prime} 30^{\prime \prime} \mathrm{E}$ & Lacustrine sediment & pIRIR 290 & Zeeden et al. (in prep.) \\
\hline C-L3789 & Ságvár, Hungary & $46^{\circ} 49^{\prime} 18^{\prime \prime} \mathrm{N}, 18^{\circ} 05^{\prime} 23^{\prime \prime} \mathrm{E}$ & Loess & pIRIR 290 & Bösken et al. (in press, a) \\
\hline C-L3791 & Ságvár, Hungary & $46^{\circ} 49^{\prime} 18^{\prime \prime} \mathrm{N}, 18^{\circ} 05^{\prime} 23^{\prime \prime} \mathrm{E}$ & Loess & pIRIR 290 & Bösken et al. (in press, a) \\
\hline$\overline{C-L 3792}$ & Ságvár, Hungary & $46^{\circ} 49^{\prime} 18^{\prime \prime} \mathrm{N}, 18^{\circ} 05^{\prime} 23^{\prime \prime} \mathrm{E}$ & Loess & pIRIR 290 & Bösken et al. (in press, a) \\
\hline C-L3793 & Ságvár, Hungary & $46^{\circ} 49^{\prime} 18^{\prime \prime} \mathrm{N}, 18^{\circ} 05^{\prime} 23^{\prime \prime} \mathrm{E}$ & Loess & pIRIR 290 & Bösken et al. (in press, a) \\
\hline C-L3795 & Bodrogkeresztúr, Hungary & $48^{\circ} 08^{\prime} 50^{\prime \prime} \mathrm{N}, 21^{\circ} 21^{\prime} 48^{\prime \prime} \mathrm{E}$ & Loess & $\mathrm{pIRIR}_{290}$ & Bösken et al. (in press, b) \\
\hline C-L3797 & rectór & "N, 2 & $\begin{array}{l}\text { Pedogenetically overprinted } \\
\text { loess }\end{array}$ & 90 & Bösken et \\
\hline C-L3799 & Bodrogkeresztúr, Hungary & $48^{\circ} 08^{\prime} 50^{\prime \prime} \mathrm{N}, 21^{\circ} 21^{\prime} 48^{\prime \prime} \mathrm{E}$ & Loess & pIRIR 290 & Bösken et al. (in press, b) \\
\hline
\end{tabular}


Stokes' Law). All steps were carried out under subdued red light conditions $(640 \pm 20 \mathrm{~nm})$. Readily prepared fine grains were pipetted onto aluminium or steel discs ( $\sim 2 \mathrm{mg}$ per aliquot in Bayreuth, $\sim 0.9-1.0 \mathrm{mg}$ in Cologne) for IRSL and pIRIR measurements. Experiments by Kreutzer et al. (2014; Table S3) have shown that pIRIR $_{225} a$-values resulting from both $1 \mathrm{mg}$ and $2 \mathrm{mg}$ of sample material per aliquot are identical within uncertainties.

\section{INSTRUMENTATION AND DATA ANALYSIS}

All measurements were carried out on Risø TL/OSL DA15/DA20 readers, equipped with infrared $(875 \pm 80 \mathrm{~nm})$ diodes for signal stimulation and an EMI 9235QB15 photomultiplier tube coupled with a Chroma D410/30x band pass filter $(410 \pm 15 \mathrm{~nm})$ for signal discrimination and detection. Artificial $\beta$-irradiation was carried out with a built-in ${ }^{90} \mathrm{Sr} /{ }^{90} \mathrm{Y} \beta$-source delivering dose rates to fine grains between $0.040 \pm 0.002$ and $0.133 \pm 0.005 \mathrm{~Gy} \mathrm{~s}^{-1}$. In Bayreuth, $\alpha$-irradiation was conducted in vacuum $\left(<10^{-2}\right.$ mbar $)$ using either the built-in ${ }^{241} \mathrm{Am}$ source $\left(0.144 \pm 0.007 \mathrm{~Gy} \mathrm{~s}^{-1}\right)$ of one of the Risø readers or an external six-seater Littlemore ${ }^{241} \mathrm{Am}$ irradiation facility (type 721/B) with a dose rate of $0.021 \pm 0.002 \mathrm{~Gy} \mathrm{~s}^{-1}$. In Cologne, the built-in $\alpha$-source of a Freiberg Instruments lexsyg research reader was used for that purpose $\left(0.197 \pm 0.004 \mathrm{~Gy} \mathrm{~s}^{-1},<1 \mathrm{mbar}\right)$. Information on the calibration of these $\alpha$-sources is given in the appendix.

Acquired luminescence data were analysed using the program Analyst (v.4.31.9; Duller, 2015). IRSL and pIRIR $_{290}$ decay curves were measured for $300 \mathrm{~s}$ (Bayreuth) or $200 \mathrm{~s}$ (Cologne) in this study, and the initial $5 \mathrm{~s}$ were integrated to give the signal with which dose response curves were constructed. Instrumental background averaged from the last $\sim 40 \mathrm{~s}$ of the decay curve was subtracted from the integrated signal.

\section{MULTIPLE ALIQUOT ADDITIVE-DOSE (MAAD) MEASUREMENTS}

Previous studies on the appropriateness of using single-aliquot regeneration (SAR) protocols for $a$-value assessment raised concerns on the validity of $\beta$-test dose correction of $\alpha$-induced luminescence signals (Mauz et al., 2006). One way of bypassing this problem is to apply multiple-aliquot additive-dose (MAAD) protocols. In this study, natural aliquots were divided into four dose groups (four aliquots each) and given equally-spaced additive $\alpha$-doses between 0 and 969 Gy. After measuring the pIRIR $_{290}$ and IRSL $_{\mathrm{F}}$ signals according to the protocol described in Table 2 (steps 2-4), the fitted dose response curve was extrapolated to the $\alpha$-dose axis and the soobtained $\alpha$-dose related to the $\beta$-dose derived from 'regu- lar' SAR $D_{\mathrm{e}}$ measurements to obtain the $a$-value. We adopted the equal pre-dose normalisation technique (Franklin and Hornyak, 1992) to reduce inter-aliquot scatter using solely $\alpha$-regeneration doses and an $\alpha$-test dose of $211 \mathrm{~Gy}$. In the course of this normalisation method, all aliquots received the same cumulative dose and heat treatment prior to test dose irradiation to consider dose-dependent sensitivity changes. To account for the pIRIR $_{290}$ residual, the signal left after $24 \mathrm{~h}$ bleaching in a solar simulator (Osram Duluxstar $24 \mathrm{~W}$ ) was subtracted (Fig. 1). In all cases, the laboratory bleaching procedure resulted in $\mathrm{IRSL}_{\mathrm{F}}$ and $\mathrm{pIRIR}_{290}$ signals close to instrumental background levels. For MAAD investigations, we chose two samples (BT1344, BT1345) with comparably small $D_{\mathrm{e}}$ values with the aim to enable a linear fit to the dose points. The MAAD dose response curve of sample BT1345 is shown in Fig. 1; resulting $a$-values are listed in Table 4.

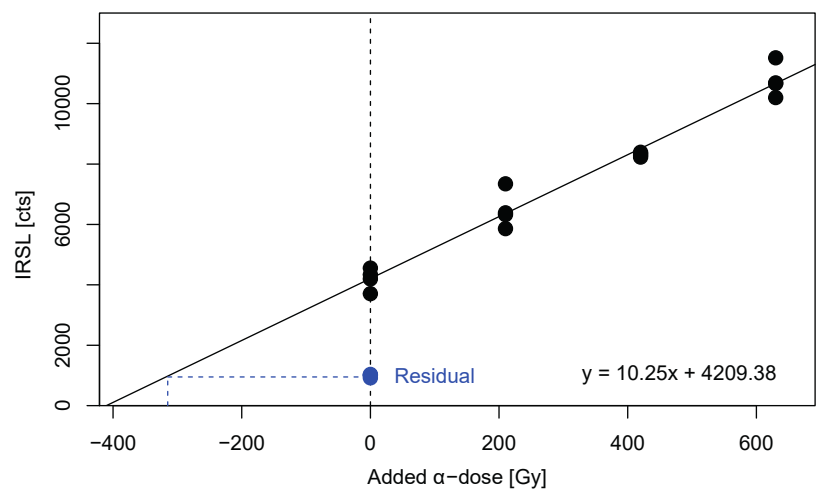

Fig. 1. Results of MAAD measurements for sample BT1345 (IRSLF protocol). The corresponding a-value is shown in Table 4.

Despite the fact that $a$-values derived from MAAD measurements may be regarded as reliable for the above mentioned reasons (no test dose correction necessary and normalisation using $\alpha$-doses only), they are nevertheless tied to some impracticalities. First, comparatively large amounts of sample material are required $(>12$ aliquots, in addition to those needed for 'regular' $D_{\mathrm{e}}$ determination). Secondly, data scatter and extrapolation of the dose response curve can cause uncertainties of dose estimates usually larger than those in SAR measurements. The following experiments hence aim at testing whether SAR measurements are a practical alternative to the MAAD approach and which measurement procedures yield the most reliable $a$-values. The pIRIR 290 protocol following Thiel et al. (2011) and the IRSL F $_{\text {potocol after Faust et }}$ al. (2015) on which the SAR measurements are based are outlined in Table 2. 
Table 2. Measurement protocols employed for a-value determination. Step 1 in the first SAR cycle is carried out using a-irradiation, while all subsequent irradiations refer to $\beta$-doses. The pIRIR290 protocol follows Thiel et al. (2011), while the IRSLF protocol was adopted from Faust et al. (2015). Stimulation times for IRSL 50 and pIRIR290 signals were $300 \mathrm{~s}$ (Bayreuth) or $200 \mathrm{~s}$ (Cologne); an IRSL readout at $325^{\circ} \mathrm{C}$ for $600 \mathrm{~s}$ (Bayreuth) or $200 \mathrm{~s}$ (Cologne) intended to fully zero IRSL traps prior to the next regeneration cycle.

\begin{tabular}{|c|c|c|c|c|c|}
\hline \multicolumn{3}{|c|}{ plRIR 290} & \multicolumn{3}{|c|}{ IRSLF } \\
\hline Step & Procedure & Signal & Step & Procedure & Signal \\
\hline 0 & Resetting of the natural signal & & 0 & Resetting of the natural signal & \\
\hline 1 & Irradiation with dose $D_{\mathrm{i}}$ & & 1 & Irradiation with dose $D_{\mathrm{i}}$ & \\
\hline 2 & Preheat $\left(320^{\circ} \mathrm{C}, 60 \mathrm{~s}\right)$ & & 2 & Preheat $\left(270^{\circ} \mathrm{C}, 120 \mathrm{~s}\right)$ & \\
\hline 3 & IR stimulation $\left(50^{\circ} \mathrm{C}, 300 \mathrm{~s}\right.$ or $\left.200 \mathrm{~s}\right)$ & & 3 & Pause (1200 s) & \\
\hline$\overline{4}$ & IR stimulation $\left(290^{\circ} \mathrm{C}, 300 \mathrm{~s}\right.$ or $\left.200 \mathrm{~s}\right)$ & $L_{x}$ & 4 & IR stimulation $\left(125^{\circ} \mathrm{C}, 300 \mathrm{~s}\right)$ & $L_{x}$ \\
\hline 5 & Irradiation with test dose $D_{\mathrm{t}}$ & & 5 & Irradiation with test dose $D_{\mathrm{t}}$ & \\
\hline 6 & Preheat $\left(320^{\circ} \mathrm{C}, 60 \mathrm{~s}\right)$ & & 6 & Preheat $\left(270^{\circ} \mathrm{C}, 120 \mathrm{~s}\right)$ & \\
\hline 7 & IR stimulation $\left(50^{\circ} \mathrm{C}, 300 \mathrm{~s}\right.$ or $\left.200 \mathrm{~s}\right)$ & & 7 & Pause (1200 s) & \\
\hline 8 & IR stimulation $\left(290^{\circ} \mathrm{C}, 300 \mathrm{~s}\right.$ or $\left.200 \mathrm{~s}\right)$ & $T_{\mathrm{x}}$ & 8 & IR stimulation $\left(125^{\circ} \mathrm{C}, 300 \mathrm{~s}\right)$ & $T_{\mathrm{x}}$ \\
\hline 9 & IR stimulation $\left(325^{\circ} \mathrm{C}, 600 \mathrm{~s}\right.$ or $\left.200 \mathrm{~s}\right)$ & & 9 & Return to step 1 & \\
\hline 10 & Return to step 1 & & & & \\
\hline
\end{tabular}

\section{SINGLE ALIQUOT REGENERATION (SAR) MEASUREMENTS}

\section{Considerations on the size of regeneration doses}

The determination of the $a$-value relies on comparing luminescence signals generated by $\alpha$ - and $\beta$-radiation. Since the $\alpha$-dose response is linear to much higher doses than the $\beta$-dose response, the $a$-value starts to change as soon as the $\beta$-dose response shows saturating behaviour (Zimmerman, 1972; Mauz et al., 2006; Kreutzer et al., 2014). It is thus important to avoid doses outside the linear range of the dose response for both $\alpha$ - and $\beta$-radiation. Depending on the individual luminescence sensitivity of each sample, we therefore tried to keep administered $\alpha$ - and $\beta$-regeneration doses as low as possible (Table 4). Due to this restriction and the fact that the intensity of pIRIR signals usually exceeds that of the $\mathrm{IRSL}_{50}$ signals for stimulation temperatures $>250^{\circ} \mathrm{C}$ (e.g., Zhang et al., 2015), the latter signal was too dim in most cases to evaluate $\operatorname{IRSL}_{50} a$-values accurately.

\section{pIRIR signal resetting prior to $\alpha$-regeneration}

A common SAR procedure to determine the $a$-value includes irradiating a zeroed aliquot with a known $\alpha$-dose, constructing a dose response curve by a series of $\beta$-regeneration cycles and finally dividing the obtained $\beta-D_{\mathrm{e}}$ by the known $\alpha$-dose. Kreutzer et al. (2014) showed for the pIRIR 225 emission of polymineral fine grain samples that the mechanism of signal resetting prior to $\alpha$-irradiation has significant influence on the resulting $a$-value. Without being able to cover the entire set of zeroing mechanisms examined by Kreutzer et al. (2014) for all of our samples, we focus here on thermallyassisted IR resetting ('hot bleach') and annealing. While samples at the Bayreuth laboratory received a hot bleach (IR stimulation at $325^{\circ} \mathrm{C}$ for $600 \mathrm{~s}$, identical to step 9 in Table 2), those in the Cologne laboratory were annealed $\left(480^{\circ} \mathrm{C}\right.$ for $\left.60 \mathrm{~s}\right)$ for the purpose of signal resetting. Both procedures cause IRSL and pIRIR $_{290}$ signal depletion down to levels indistinguishable from instrumental background. For three samples from the Cologne laboratory (C-L3787, C-L3789, C-L3793) and one from the Bayreuth laboratory (BT1344) both resetting procedures were applied in parallel. Three of these samples gave identical $a$-values for both resetting methods, while one (C-L3789) showed differing results (based on the standard deviation of individual aliquots) (Fig. 2; Table 4). Observed differences between the resetting procedures are not significant (Welch two sample $t$-test: $t=0.85, d f=8.0, p=0.42$ ).

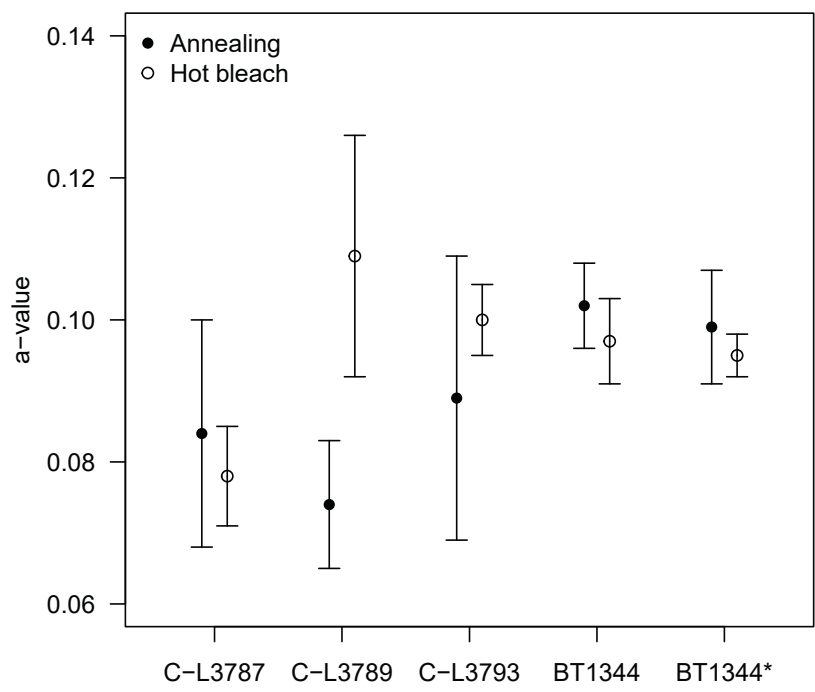

Fig. 2. Comparison of a-values determined following different luminescence signal resetting modes. Each data point represents 2-4 individual a-value measurements; the error bars show the standard deviation. All measurements were carried out with aliquots of $\sim 1 \mathrm{mg}$ sample material, except for BT1344* ( 2 mg sample material per aliquot). 


\section{Sensitivity correction of an $\alpha$-regenerated signal by a $\beta$-test dose}

One basic assumption of SAR protocols is that the luminescence signal of a test dose measurement monitors the sample's luminescence sensitivity to the preceding regenerative $\beta$-dose (e.g., Murray and Wintle, 2000). Whether this assumption holds true for an $\alpha$-regenerated signal that is monitored by a $\beta$-test dose measurement is, however, unclear. Accurate sensitivity correction can be expected if the $\alpha$-induced luminescence signal $\left(L_{\alpha}\right)$ and the $\beta$-test dose signal $\left(T_{\beta}\right)$ are directly proportional to each other in the course of repeated constant-dose $L_{\alpha}$ and $T_{\beta}$ cycles. In addition, in a plot of $T_{\beta}$ vs. $L_{\alpha}$ the y-axis intercept should be small compared to luminescence intensity (Murray and Mejdahl, 1999). Previous investigations of a silt-sized quartz sample by Mauz et al. (2006) showed varying behaviour in the proportionality of $L_{\alpha}$ and $T_{\beta}$ signals, with one aliquot fulfilling these requirements, while the other three failed. Equivalent experiments for silt-sized polymineral samples have not yet been carried out.

We therefore measured repeated $L_{\alpha}-T_{\beta}$ cycles for seven polymineral samples (four aliquots each) while applying the two measurement protocols listed in Table 2. Natural signals were zeroed prior to $\alpha$-regeneration by means of a hot bleach and $\alpha$-doses were chosen according to luminescence signal intensity (BT1257, BT1258, BT1259: 298 Gy; BT1342, BT1343, BT1423, BT1426: 199 Gy); the $\beta$-test dose was kept constant at 5 Gy. For practical reasons, the major part of measurements consisted of three cycles of $\alpha$-irradiation using the Littlemore facility and $\beta$-irradiation in a Risø reader. However, to check for potential loss of sample material during repeated transport between irradiation facilities, we conducted reference measurements of seven $L_{\alpha}-T_{\beta}$ cycles for samples BT1258 and BT1259 (IRSL F and pIRIR ${ }_{290}$ ) using both the built-in $\alpha$ - and $\beta$-source of one of the Risø readers, i.e. sample transport was not necessary in this case. $L_{\alpha}-T_{\beta}$ data were fitted with a linear function. Representative results are shown in Fig. 3.

As evident from Fig. 3, the major part of studied samples $(\sim 70 \%)$ revealed direct proportionality between $L_{\alpha}$ and $T_{\beta}$. There is a substantial offset on the y-axis only for few samples (e.g., BT1343 in Fig. 3), rendering the SAR procedure for $a$-value determination inappropriate for these. The relative change of the $L_{\alpha} / T_{\beta}$ ratio after three and seven regeneration cycles for the $\mathrm{IRSL}_{\mathrm{F}}$ and $\mathrm{pIRIR}_{290}$ protocols is shown in Table 3 for samples BT1258 and

Table 3. Relative change of the $L_{\alpha} / T_{\beta}$ ratio after repeated $L_{\alpha}-T_{\beta}$ cycles (see main text for further information).

\begin{tabular}{lll|ll}
\hline Sample & \multicolumn{2}{c|}{ BT1258 } & \multicolumn{2}{c}{ BT1259 } \\
\hline Protocol & $\mathrm{IRSL}_{\mathrm{F}}$ & $\mathrm{pIRIR} \mathrm{R}_{290}$ & $\mathrm{IRSL}_{\mathrm{F}}$ & $\mathrm{pIRIR}_{290}$ \\
\hline 3 cycles & $6 \%$ & $3 \%$ & $9 \%$ & $8 \%$ \\
\hline 7 cycles & $5 \%$ & $7 \%$ & $12 \%$ & $13 \%$ \\
\hline
\end{tabular}

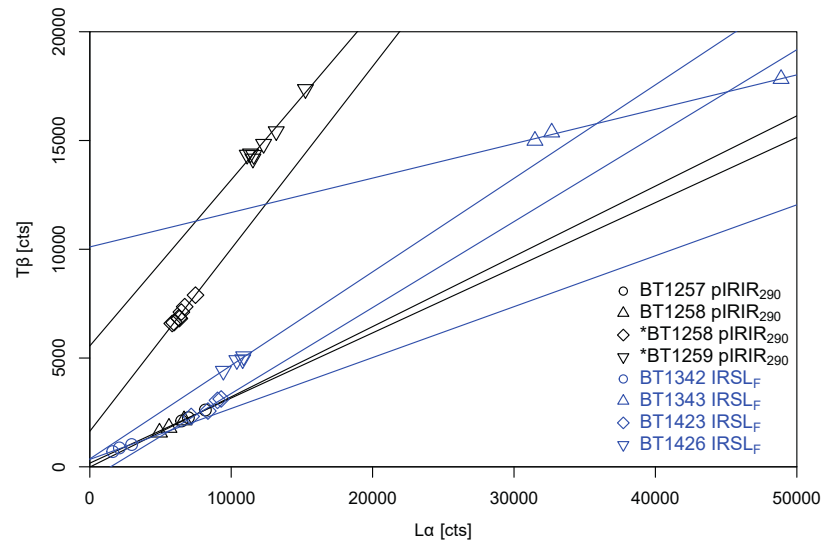

Fig. 3. Results of the repeated $L_{\alpha}-T_{\beta}$ measurements. Data were fitted with a linear function; pIRIR 290 results are shown in black, IRSL $L_{F}$ results in blue. The asterisk indicates that seven $L_{\alpha}-T_{\beta}$ cycles were measured without removing the samples from the luminescence reader, while the other samples were transferred from the a-irradiation facility to the luminescence reader three times (see main text for further details).

BT1259. Furthermore, we could not observe any systematic trend with respect to sample provenance and measurement protocol for the fulfilment of the $L_{\alpha}-T_{\beta}$ requirement.

\section{Variation of $a$-values among samples and measure- ment protocols}

Since the SAR approach as outlined in the previous sections appears to be appropriate for $\alpha$-efficiency determination for the majority of polymineral samples, we employed it to determine the $a$-value for the 47 samples listed in Table 1. For each sample, up to eleven aliquots were analysed and the arithmetic average calculated, along with the standard deviation (SD, at $1 \sigma$ confidence level) and the averaged measurement uncertainty $\Delta a=$ $\left[\left(\Delta a_{1}^{2}+\Delta a_{2}^{2}+\ldots+\Delta a_{n}^{2}\right) / n\right]^{0.5}$ (with $\Delta a_{n}$ being the uncertainty of an individual aliquot, and $n$ the number of aliquots) in order to both depict the scatter of several aliquots of one sample and the uncertainties associated with individual $a$-values derived from a single aliquot. Results are summarised in Fig. 4 and compiled numerically in Table 4.

The $a$-values for the IRSL $_{\mathrm{F}}$ protocol yield an average of $0.081 \pm 0.008(n=24$; unweighted average with SD) and $0.074 \pm 0.009(n=24$; error-weighted average with $\mathrm{SD}$ ) (Table 4 and Fig. 4). Excluding the MAAD $a$-value of sample BT1344 (outlier according to Dixon's test with $p=0.01$; Rorabacher, 1991) produces average $\mathrm{pIRIR}_{290}$ $a$-values for samples measured in Bayreuth of $0.085 \pm 0.010 \quad(n=18$; unweighted average $)$ and $0.083 \pm 0.011(n=18$; error-weighted average $)$. Corresponding pIRIR ${ }_{290} a$-values for the measurements conducted in Cologne are $0.101 \pm 0.014(n=22$; unweighted average $)$ and $0.095 \pm 0.013(n=22$; error-weighted aver- 
Table 4. Results of a-value determination. In contrast to Table 1, samples are grouped according to the measurement protocol used for a-value determination. $n$ is the number of measured aliquots per sample. The a-value is derived as the arithmetic mean of individual aliquots of one sample; the averaged measurement uncertainty $\Delta a$ is calculated using the formula $\Delta a=\left[\left(\Delta a_{1}{ }^{2}+\Delta a_{1}{ }^{2}+\ldots+\Delta a_{n}{ }^{2}\right) / n\right]^{0.5}$; $S D$ is the standard deviation. The lowtemperature IRSL readout of sample C-L3789 was carried out both at $50^{\circ} \mathrm{C}$ and $80^{\circ} \mathrm{C}$, as indicated in the first column. Systematic errors relating to $\alpha$ - and $\beta$-source calibration are not considered in this compilation.

\begin{tabular}{|c|c|c|c|c|c|c|c|}
\hline Sample code & Protocol & Resetting & $\alpha$-dose (Gy) & $n$ & $a$-value & $\Delta a$ & $\mathrm{SD}(1 \sigma)$ \\
\hline$\overline{B T 1257}$ & pIRIR 290 & Hot bleach & 298 & 4 & 0.078 & 0.005 & 0.005 \\
\hline BT1258 & pIRIR 290 & Hot bleach & 298 & 4 & 0.087 & 0.005 & 0.008 \\
\hline BT1259 & $\mathrm{pIRIR} 290$ & Hot bleach & 298 & 4 & 0.083 & 0.004 & 0.007 \\
\hline BT1344 & pIRIR 290 & Hot bleach & 298 & 4 & 0.084 & 0.006 & 0.009 \\
\hline BT1344 & pIRIR ${ }_{290}$ MAAD & Hot bleach & - & - & 0.035 & 0.004 & - \\
\hline$\overline{B T 1345}$ & pIRIR 290 & Hot bleach & 633 & 4 & 0.102 & 0.009 & 0.011 \\
\hline BT1345 & pIRIR ${ }_{290}$ MAAD & Hot bleach & - & - & 0.075 & 0.008 & - \\
\hline$\overline{B T 1513}$ & pIRIR 290 & Hot bleach & 298 & 3 & 0.089 & 0.005 & 0.006 \\
\hline$\overline{B T 1515}$ & pIRIR 290 & Hot bleach & 298 & 3 & 0.077 & 0.009 & 0.010 \\
\hline$\overline{B T 1517}$ & pIRIR 290 & Hot bleach & 298 & 3 & 0.076 & 0.003 & 0.003 \\
\hline BT1519 & pIRIR 290 & Hot bleach & 298 & 3 & 0.071 & 0.005 & 0.003 \\
\hline BT1525 & pIRIR 290 & Hot bleach & 298 & 3 & 0.094 & 0.008 & 0.011 \\
\hline BT1526 & pIRIR 290 & Hot bleach & 298 & 3 & 0.107 & 0.008 & 0.004 \\
\hline BT1527 & pIRIR 290 & Hot bleach & 298 & 3 & 0.090 & 0.010 & 0.006 \\
\hline BT1528 & pIRIR 290 & Hot bleach & 298 & 3 & 0.075 & 0.004 & 0.007 \\
\hline BT1401 & pIRIR 290 & Hot bleach & 373 & 2 & 0.091 & 0.008 & 0.008 \\
\hline$\overline{B T 1415}$ & pIRIR 290 & Hot bleach & 298 & 4 & 0.085 & 0.004 & 0.006 \\
\hline BT1416 & pIRIR 290 & Hot bleach & 298 & 4 & 0.083 & 0.003 & 0.003 \\
\hline$\overline{B T 1417}$ & pIRIR 290 & Hot bleach & 298 & 4 & 0.091 & 0.004 & 0.007 \\
\hline C-L3704 & $\mathrm{pIRIR} 290$ & Annealing & 79 & 2 & 0.109 & 0.006 & 0.009 \\
\hline$\overline{C-L 3707}$ & pIRIR 290 & Annealing & 79 & 2 & 0.115 & 0.006 & 0.008 \\
\hline C-L3778 & pIRIR 290 & Annealing & 79 & 3 & 0.116 & 0.006 & 0.010 \\
\hline C-L3780 & $\mathrm{plRIR} 290$ & Annealing & 79 & 2 & 0.108 & 0.007 & 0.015 \\
\hline$\overline{C-L 3784}$ & pIRIR 290 & Annealing & 79 & 3 & 0.119 & 0.010 & 0.016 \\
\hline$\overline{C-L 3786}$ & $\mathrm{plRIR}_{290}$ & Annealing & 79 & 2 & 0.085 & 0.006 & 0.009 \\
\hline C-L3787 & $\mathrm{pIRIR} \mathrm{R}_{290}$ & Hot bleach & 197 & 1 & 0.078 & 0.007 & - \\
\hline C-L3787 & plRIR 290 & Annealing & 394 & 6 & 0.084 & 0.003 & 0.016 \\
\hline C-L3788 & $\mathrm{pIRIR}_{290}$ & Annealing & 394 & 6 & 0.105 & 0.004 & 0.010 \\
\hline$\overline{C-L 3789(50 C)}$ & pIRIR 290 & Annealing & 79 & 3 & 0.103 & 0.007 & 0.012 \\
\hline C-L3789 (80C) & pIRIR 290 & Hot bleach & 197 & 3 & 0.109 & 0.006 & 0.017 \\
\hline$\overline{C-L 3789(80 \mathrm{C})}$ & pIRIR 290 & Annealing & 296 & 11 & 0.074 & 0.003 & 0.009 \\
\hline$\overline{C-L 3791}$ & plRIR 290 & Annealing & 394 & 6 & 0.084 & 0.003 & 0.016 \\
\hline C-L3792 & pIRIR 290 & Annealing & 394 & 5 & 0.091 & 0.004 & 0.016 \\
\hline C-L3793 & pIRIR 290 & Hot bleach & 197 & 2 & 0.100 & 0.004 & 0.005 \\
\hline C-L3793 & $\mathrm{pIRIR} \mathrm{R}_{290}$ & Annealing & 394 & 6 & 0.089 & 0.003 & 0.020 \\
\hline C-L3795 & plRIR 290 & Annealing & 394 & 5 & 0.107 & 0.004 & 0.005 \\
\hline C-L3797 & pIRIR 290 & Annealing & 394 & 6 & 0.100 & 0.004 & 0.005 \\
\hline C-L3799 & pIRIR 290 & Annealing & 394 & 3 & 0.096 & 0.004 & 0.007 \\
\hline C-L4029 & pIRIR 290 & Hot bleach & 50 & 5 & 0.113 & 0.009 & 0.010 \\
\hline C-L4030 & pIRIR 290 & Hot bleach & 50 & 5 & 0.120 & 0.012 & 0.010 \\
\hline C-L4031 & pIRIR 290 & Hot bleach & 50 & 5 & 0.115 & 0.010 & 0.019 \\
\hline BT1337 & IRSLF & Hot bleach & 199 & 4 & 0.077 & 0.014 & 0.005 \\
\hline BT1339 & IRSLF & Hot bleach & 199 & 4 & 0.074 & 0.003 & 0.003 \\
\hline BT1340 & IRSLF & Hot bleach & 199 & 4 & 0.096 & 0.009 & 0.002 \\
\hline BT1341 & IRSLF & Hot bleach & 199 & 4 & 0.099 & 0.014 & 0.007 \\
\hline BT1342 & IRSLF & Hot bleach & 199 & 4 & 0.086 & 0.010 & 0.008 \\
\hline BT1343 & $I^{\prime R S L_{F}}$ & Hot bleach & 199 & 4 & 0.078 & 0.003 & 0.003 \\
\hline BT1344 & IRSLF & Hot bleach & 199 & 4 & 0.091 & 0.006 & 0.005 \\
\hline BT1344 & IRSLF MAAD & Hot bleach & - & - & 0.079 & 0.006 & - \\
\hline BT1345 & IRSLF & Hot bleach & 199 & 4 & 0.085 & 0.007 & 0.003 \\
\hline$\overline{B T 1345}$ & IRSLF MAAD & Hot bleach & - & - & 0.069 & 0.004 & - \\
\hline
\end{tabular}


Table 4. Continuation.

\begin{tabular}{|c|c|c|c|c|c|c|c|}
\hline Sample code & Protocol & Resetting & $\alpha$-dose (Gy) & $n$ & a-value & $\Delta a$ & $\operatorname{SD}(1 \sigma)$ \\
\hline BT1421 & IRSLF & Hot bleach & 199 & 4 & 0.084 & 0.006 & 0.006 \\
\hline BT1423 & $\mathrm{IRSL}_{\mathrm{F}}$ & Hot bleach & 199 & 4 & 0.082 & 0.006 & 0.005 \\
\hline BT1424 & IRSLF & Hot bleach & 199 & 4 & 0.087 & 0.005 & 0.011 \\
\hline BT1425 & $\mathrm{IRSL}_{\mathrm{F}}$ & Hot bleach & 199 & 4 & 0.077 & 0.005 & 0.005 \\
\hline BT1426 & IRSLF & Hot bleach & 199 & 4 & 0.077 & 0.003 & 0.005 \\
\hline BT1432 & $\mathrm{IRSLF}_{\mathrm{F}}$ & Hot bleach & 199 & 4 & 0.080 & 0.004 & 0.005 \\
\hline BT1513 & IRSLF & Hot bleach & 298 & 3 & 0.072 & 0.003 & 0.001 \\
\hline BT1514 & IRSLF & Hot bleach & 298 & 4 & 0.081 & 0.005 & 0.005 \\
\hline$\overline{\text { BT1515 }}$ & IRSLF & Hot bleach & 298 & 3 & 0.078 & 0.006 & 0.008 \\
\hline BT1517 & IRSLF & Hot bleach & 298 & 3 & 0.073 & 0.002 & 0.002 \\
\hline BT1519 & IRSLF & Hot bleach & 298 & 3 & 0.082 & 0.005 & 0.003 \\
\hline BT1525 & IRSLF & Hot bleach & 298 & 3 & 0.085 & 0.005 & 0.004 \\
\hline BT1528 & IRSLF & Hot bleach & 298 & 3 & 0.066 & 0.003 & 0.001 \\
\hline$\overline{\text { BT1529 }}$ & IRSLF & Hot bleach & 298 & 4 & 0.077 & 0.004 & 0.005 \\
\hline
\end{tabular}

age). Although pIRIR $290 a$-values from both laboratories overlap within $1 \sigma$ standard deviation (Fig. 4), their difference is significant (Welch two sample $t$-test: $t=3.96$, $d f=36.6, p<0.01)$. Contrarily, $a$-values measured with two different protocols in the Bayreuth laboratory $\left(\mathrm{pIRIR}_{290}\right.$ and $\mathrm{IRSL}_{\mathrm{F}}$ ) derive from one common distribution, i.e. the difference of their means is not significant (Welch two sample $t$-test: $t=1.7, d f=30.4, p=0.1$ ). Finally, the variation between samples from different sample locati ons (e.g. sampled sections) measured with the pIRIR $_{290}$ protocol was investigated (Fig. 5). The $F$ test revealed that there are significant differences in the mean $a$-values between the tested sample locations
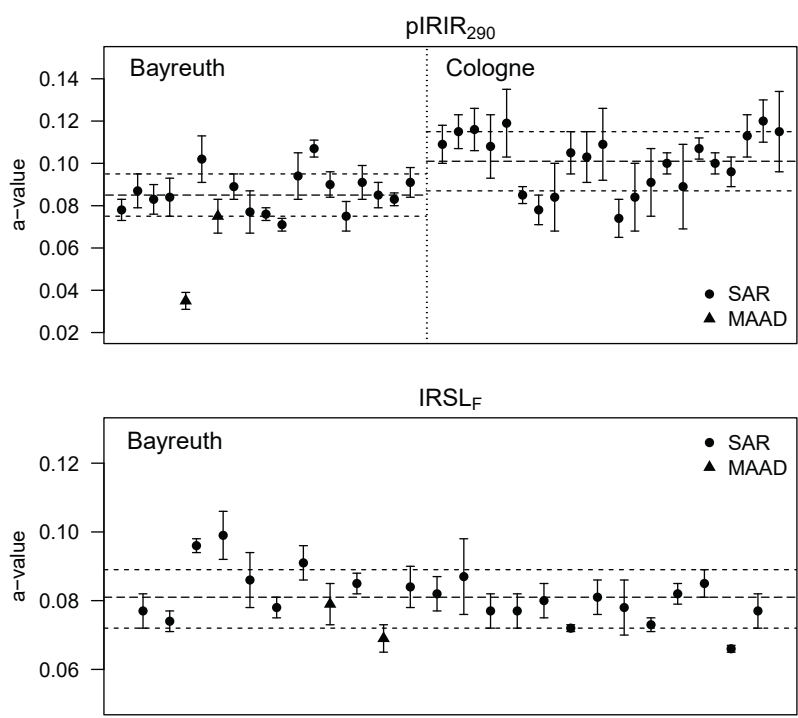

Fig. 4. Graphical summary of pIRIR 290 and $I R S L_{F}$ a-values measured in Bayreuth and Cologne. The dashed lines indicate the unweighted average and its standard deviation (1б). Data points represent the average of 1-11 aliquots (see Table 4) and are plotted with the corresponding standard deviation (10).
$\left(F_{9,23}=4.17, p<0.01\right)$, i.e., the explained variation between mean $a$-values of different locations exceeds the unexplained variation within the $a$-values of one sampled profile. Specifically, we observed significant differences in the $a$-values from Vrsac and Titel (C-L4029-4031 and BT1257-1259; Tukey post-hoc-test: $p=0.01)$, Vrsac and Jable 1, Fuerteventura (C-L4029-4031 and BT1513, BT1515, BT1517; Tukey post-hoc-test: $\mathrm{p}<0.01$ ), and Vrsac and Vârghis (C-L4029-4031 and BT1415-1416; Tukey post-hoc-test: $p=0.04)$. There is no significant difference between sample locations for the $a$-values determined with the IRSL $_{F}$ protocol $\left(F_{6,14}=2.56\right.$, $p=0.07)$.

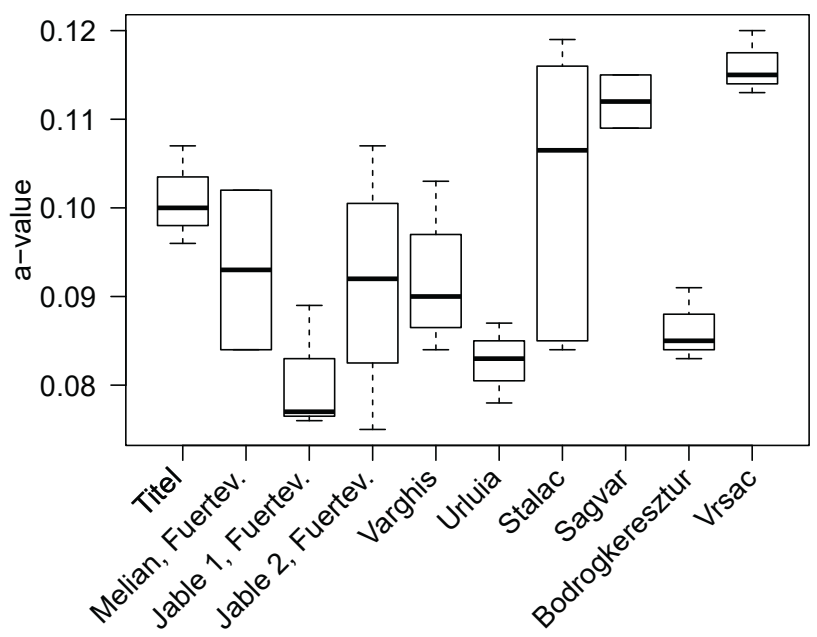

Fig. 5. Boxplot of pIRIR 290 a-values grouped according to sampled outcrops. Further sampling information and numerical results are given in Tables 1 and 4. 


\section{Comparative measurements between laboratories}

To investigate whether pIRIR ${ }_{290} a$-values are reproducible on various luminescence readers and with respect to specific laboratory routines, we measured samples prepared in Bayreuth (BT1344) in the Cologne laboratory and vice versa (C-L3778, C-L3788, C-L3791, C-L3707), using the same measurement protocol. However, laboratory-specific resetting mechanisms (Bayreuth: hot bleach; Cologne: annealing) and aliquot size (Bayreuth; $\sim 2 \mathrm{mg}$; Cologne: $\sim 0.9-1.0 \mathrm{mg}$ ) were retained.

Results of these five samples are shown in Fig. 6. The pIRIR $_{290} a$-values obtained are different (by $\sim 20-30 \%$ ) for the two laboratories, with the values derived in Cologne mostly exceeding those measured in Bayreuth. Nevertheless, these differences are not significant (Welch two sample $t$-test: $t=1.82, d f=7.7, p=0.11$ ).

Comparative measurements of sample BT1344 in Cologne using aliquot sizes of $\sim 1.0$ and $\sim 2.0 \mathrm{mg}$ yielded identical $a$-values of $0.097 \pm 0.006$ and $0.095 \pm 0.006$, respectively (Welch two sample $t$-test: $t=0.53, d f=4.8$, $p=0.62$; see also Fig. 2). The pIRIR ${ }_{290} a$-value hence appears to be largely insensitive to the amount of sample material per aliquot, in accordance to the findings by Kreutzer et al. (2014) for the pIRIR 225 -value.

In order to further study the potential reasons for differing $a$-values of the same samples as measured in the two laboratories, we aimed at testing whether there is an offset in actual reading temperature of the two luminescence readers used for the comparative measurements. Therefore, we measured the $D_{\mathrm{e}}$ on a set of fresh aliquots from samples C-L3788 and C-L3791 in Bayreuth, employing a pIRIR protocol as outlined in Table 2 with three different pIRIR readout temperatures $(270,290$, $310^{\circ} \mathrm{C}$ ), while the preheat temperatures were set $30^{\circ} \mathrm{C}$ lower than the respective stimulation temperatures. Re-

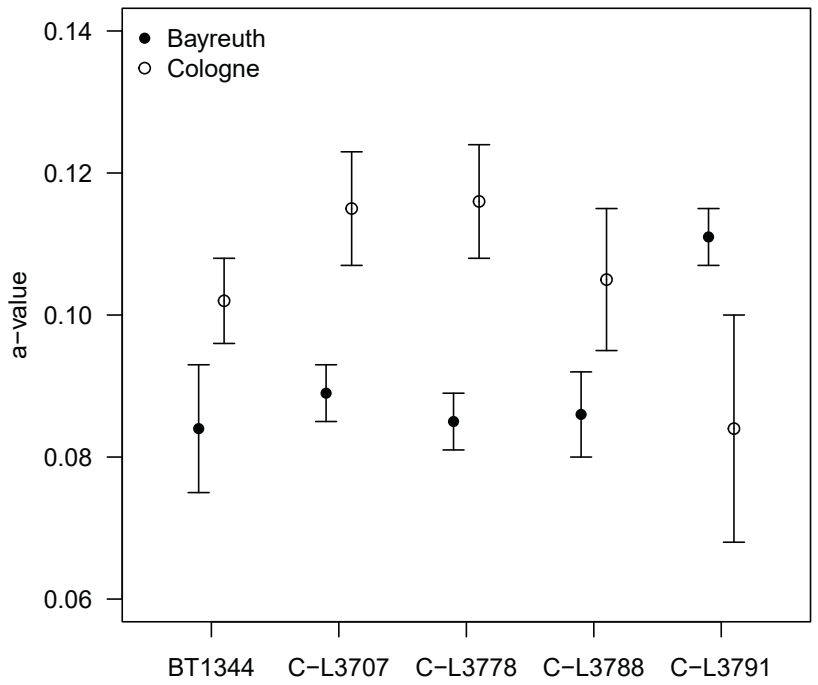

Fig. 6. Results of comparative a-value measurements between the two involved laboratories. Data points represent 2-6 aliquots and are plotted along with the respective standard deviation. sults are shown in Fig. 7 and indicate that at least for sample C-L3788 the $D_{\mathrm{e}}$ is rather sensitive to slight variations in preheat and measurement temperature. While for the pIRIR 270 protocol the $D_{\mathrm{e}}$ amounts to $\sim 245 \mathrm{~Gy}$, it progressively decreases by more than $37 \%$ for the pIRIR 290 $\left(D_{\mathrm{e}} \sim 203 \mathrm{~Gy}\right)$ and the pIRIR $310\left(D_{\mathrm{e}} \sim 154 \mathrm{~Gy}\right)$ protocols. The decrease in $D_{\mathrm{e}}$ with pIRIR measurement temperature is less pronounced for sample C-L3791, with a reduction from $\sim 100$ Gy to $\sim 85$ Gy. Reconciling these results with the $D_{\mathrm{e}}$ values of the same samples measured in Cologne with the pIRIR 290 protocol $(149 \pm 8$ Gy and $79 \pm 4$ Gy for C-L3788 and C-L3791, respectively) suggests an offset of actual measurement temperature of $\sim 20^{\circ} \mathrm{C}$ in the range $270-310^{\circ} \mathrm{C}$.

\section{DISCUSSION}

Our experiments on the correction of sensitivity changes induced by an $\alpha$-regeneration dose by means of a $\beta$-test dose indicate that for the majority of the investigated samples the SAR protocol (recovery of a known $\alpha$-dose with $\beta$-SAR cycles) is suitable to determine reliable $a$-values. This procedure is less time- and materialconsuming than MAAD protocols, for which sensitivity changes should not have any effect on the results. Comparative $a$-values derived from SAR and MAAD protocols for four samples (pIRIR 290 and IRSL $_{\mathrm{F}}$ for two samples each; Table 4) are not in agreement within $1 \sigma$ uncertainties, but are consistent with the overall $a$-value distribution of the respective IRSL signal and laboratory (see Fig. 4; except for the MAAD pIRIR 290 -value of sample BT1344, which could be classified as a statistically sig-

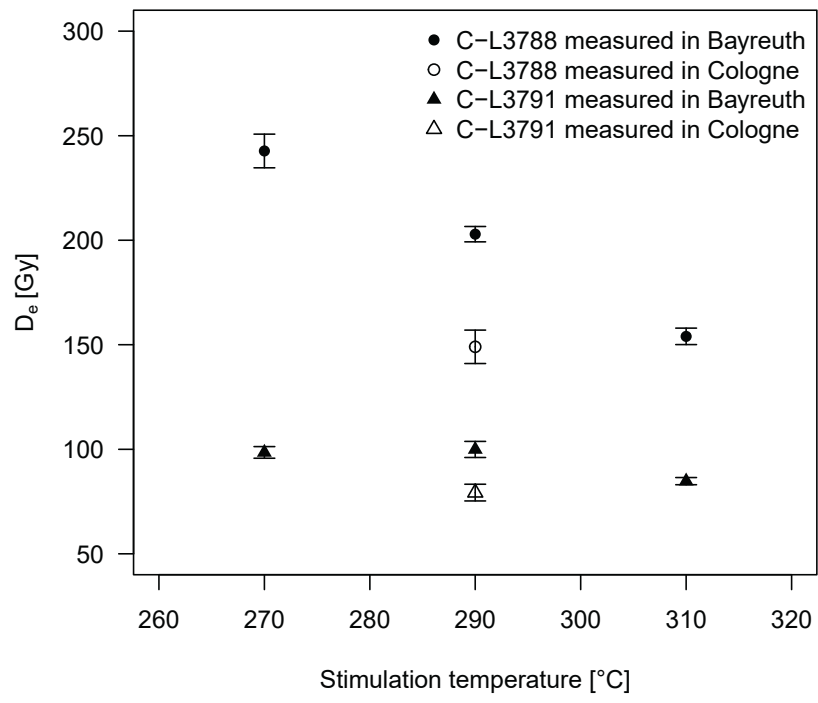

Fig. 7. Equivalent doses determined with the pIRIR protocol at varying reading temperatures $\left(270,290,310^{\circ} \mathrm{C}\right)$. Further technical details are given in the main text. A comparative dose estimate derived in the Cologne laboratory using the pIRIR 290 protocol is indicated with open symbols. Error bars represent the standard deviation of contributing aliquots. 
nificant outlier). Therefore, it can be concluded that SAR protocols are a valid procedure to determine IRSL $a$-values of polymineral silt-sized samples, at least for the majority of samples investigated in this study.

The assessment whether or not there is a common $a$-value for polymineral samples measured with several infrared stimulated luminescence protocols is not straightforward. While $a$-values appear to be consistent within one laboratory environment, there are discrepancies when comparing $a$-values that were obtained using different measurement setups. Although comparative measurements on the same samples in the two laboratories showed differences in $a$-values, these were not significant (but $n=5$ only). However, considering the entire data set it appears that the $a$-values measured in this study are less dependent on sample origin and lithology, but rather on the measurement equipment and laboratory routines. Since slight variations in experimental conditions may affect the characteristics (anomalous fading, residual signals) of (post-)IRSL signals, measured $a$-values are probably only valid for this respective experimental setup (type of sample carriers, luminescence reader etc.), and $D_{\mathrm{e}}$ and $a$-value measurements on a sample should be carried out with the same setup. Specifically, possible technical reasons for the trend of difference in $a$-values between laboratories could be the calibration of the $\alpha$ - and $\beta$-sources, thermal lag or the temperaturecalibration of the heating elements in the readers, which seem to be offset, as indicated by the comparative measurements described in the last section. Similar effects were observed in a previous interlaboratory comparison study of the $110^{\circ} \mathrm{C}$ thermoluminescence peak of quartz (Schmidt et al., 2018). The findings from the $\mathrm{pIRIR}_{290} D_{\mathrm{e}}$ comparison of the same samples within two laboratory environments (Fig. 7) suggest that the $\alpha$-source calibration is not the sole cause responsible for the discrepancy in $a$-values between laboratories. For samples with IRSL $_{50}$ signals just high enough to permit determination of rough $a$-value estimates, there is the tendency of higher average $\mathrm{IRSL}_{50} a$-values in Cologne $(0.086 \pm 0.012, n$ $=15)$ as compared to Bayreuth $(0.074 \pm 0.009, n=10)$. Since temperature deviations at $50^{\circ} \mathrm{C}$ stimulation temperature should be negligible, it appears that systematic shifts in temperature cannot explain the observed $a$-value differences alone. Rather, an interaction of the influencing factors described above seems to cause the observed variation in $a$-values. The aliquot size ( $\sim 1 \mathrm{mg}$ vs. $\sim 2 \mathrm{mg}$ per aliquot) and the mode of signal resetting, however, do not appear to influence the $a$-value significantly. It is noteworthy that the pIRIR ${ }_{290} a$-values derived after annealing (Cologne) and after hot bleach (Bayreuth) match well with the pIRIR $225 a$-values of Kreutzer et al. (2014) obtained with comparable resetting mechanisms. Although the comparison of the two resetting mechanisms in our study did not reveal any significant differences in the resulting $a$-values, a consistent pattern with higher $a$-values after annealing emerges. For future research, it might be advisable to test this with more samples and interlaboratory comparisons.

The slight differences in the pIRIR 290 measurement protocol (cf. Table 2) are unlikely to be the source of $a$-value variations between the two laboratories, because $\beta$-regeneration doses and hence signal intensities were usually low. Therefore, pIRIR 290 signals always reached instrumental background levels at the end of a regenerative measurement and signal carry-over into the test dose cycle as observed by Colarossi et al. (2018) appears improbable.

Contrasting the $a$-values obtained from different profiles revealed no provenance-related difference for the samples measured with the IRSL $\mathrm{F}_{\mathrm{F}}$ protocol. However, these samples were all taken on Fuerteventura in similar geomorphological settings and show comparable geochemical composition. Contrarily, we detected some provenance-related differences between the samples measured with the pIRIR 290 protocol. It is noteworthy though that these are mainly associated with the only lacustrine archive (Vrsac, Serbia) tested. This might suggest different $a$-values for different types of lithology or sedimentary archives; a statement, however, which needs further investigation. Furthermore, it is possible that slight provenance-related differences in $a$-values are masked by the variation induced through the differences in experimental setup. Therefore, even if there were systematic trends in $a$-values among samples with different lithology, they would not be discernible given the measurement uncertainties. This is supported by the fact that within one laboratory, the $a$-values for most of the samples are statistically the same.

The study of Kreutzer et al. (2014) showed for five loess samples from Saxony that the $a$-value appears to rise with increasing sample temperature during measurement (by $0.023 \pm 0.012$ for $\mathrm{IRSL}_{50}$ and $\mathrm{pIRIR}_{225}$, respectively, on polymineral fine grains). This trend could not be confirmed with the current data set where the average $a$-values obtained with the IRSL $_{\mathrm{F}}$ and pIRIR $_{290}$ protocols are statistically indistinguishable. Considering $a$-values employed in previous applications of the pIRIR 290 protocol (e.g., $0.08 \pm 0.02$ in Thiel et al., 2011; or $0.07 \pm 0.02$ in Preusser et al., 2014) and the dataset compiled here, it is conceivable that continuing use of literature values could lead to slight, but systematic age overestimation.

Taken previous and the current data together, the $a$ value of IRSL signals from polymineral loess samples appears to range between 0.08 and 0.11 , and whenever an individual assessment of $a$-values is not feasible (what is, however, highly encouraged), an increased uncertainty level of $30 \%$ could account for the variation in $a$-values caused by differences in measurement equipment and laboratory routines. Nevertheless, to avoid systematic errors in age determination, $a$-values should be measured as accurately as possible for each set of samples and specific measurement setup. 


\section{CONCLUSION}

The analyses conducted in the frame of $a$-value measurements of 47 polymineral silt-samples with two different IRSL measurement protocols $\left(\mathrm{pIRIR}_{290}\right.$ and $\mathrm{IRSL}_{\mathrm{F}}$ ) lead to the following conclusions:

- The SAR protocol appears to be appropriate for determining IRSL $a$-values.

- Within one laboratory environment $a$-values arise from one common statistical population.

- Determining a common and accurate $a$-value, independent of sample mineralogy, provenance and measurement equipment, remains challenging due to an inherent variation between different laboratory environments.

- Measurement equipment seems to exert significant influence on $a$-value results. Therefore, the same luminescence reader should be used for both dose and $a$-value determination.

- For the samples investigated, the $a$-values for the $\mathrm{IRSL}_{\mathrm{F}}$ signal average to $0.081 \pm 0.008$ (unweighted) and range from $0.085 \pm 0.010$ (Bayreuth laboratory) to $0.101 \pm 0.014$ (Cologne laboratory) for the pIRIR 290 signal.

\section{ACKNOWLEDGEMENTS}

Part of the investigations were carried out within CRC 806 "Our way to Europe", subproject B1 "The Eastern Trajectory: Last Glacial Palaeogeography and Archaeology of the Eastern Mediterranean and of the Balkan Peninsula" and F2 "Application of Luminescence and Electron-Spin-Resonance-Dating in Geoarchaeological Studies", supported by the DFG (Deutsche Forschungsgemeinschaft, grant number INST 216/596-2). In addition, part of the work was financed by the DFG (grant number SCHM 3051/1-1). We thank Dr. Anja Zander and Dr. Nicole Klasen for their support in the Cologne Luminescence Laboratory and for extending our dataset, and Prof. Dr. Markus Fuchs and David Strebler for providing information on the $\alpha$-source calibration in Bayreuth and Cologne. This calibration would not have been possible without the generous support of Dr. Annette Kadereit and her team at the luminescence laboratory in Heidelberg. We are indebted to Prof. Dr. Frank Lehmkuhl and Dr. Wolfgang Römer (RWTH Aachen University) as well as Katja Reinhardt (University of Bayreuth) for their support and suggestions concerning statistical data evaluation.
This publication was funded by the German Research Foundation (DFG) and the University of Bayreuth in the funding programme Open Access Publishing.

\section{APPENDIX}

\section{Alpha-source calibration}

The $\alpha$-source located in the Bayreuth laboratory was cross-calibrated against the six-seater Littlemoore $\alpha$-source (type 721/B) in the Heidelberg luminescence laboratory by means of a multiple-aliquot regenerative (MAR) dose protocol. Three sets of six aliquots of polymineral fine grains $(\sim 4-11 \mu \mathrm{m})$ extracted from loess were bleached in a Hönle solar simulator and $\alpha$-irradiated with doses of 42, 84 and $126 \mathrm{~Gy}$. Another set of six aliquots was bleached in the same manner but $\alpha$-irradiated with the source in Bayreuth. The resulting integrated IRSL signals were then interpolated onto the dose response curve built using the aliquots irradiated in Heidelberg. The $\alpha$-dose rate relevant for the source in Bayreuth was obtained from the ratio of determined MAR $\alpha$-dose and the time of irradiation.

Like the $\alpha$-source in Bayreuth, the $\alpha$-source in the lexsyg research reader in the Cologne luminescence laboratory was cross-calibrated against the Heidelberg Littlemoore $\alpha$-irradiation facility. For the calibration procedure, fine grain $(\sim 4-11 \mu \mathrm{m})$ quartz was used, from which the natural signal was reset by heating the material at $360^{\circ} \mathrm{C}$ for $\sim 2 \mathrm{~h}$. The material was divided into two subsets of 24 aliquots each, which received two different $\alpha$-doses (corresponding to 30 and $60 \mathrm{~min}$ irradiation time). These doses were recovered by means of a SAR protocol using $\alpha$-regeneration and $\alpha$-test doses. Optimal measurement parameters for this protocol were determined beforehand according to the results of performance tests such as a preheat plateau test. Dose response curves constructed from the signal of the first $\sim 1.3 \mathrm{~s}$ of the OSL decay curve (minus a background averaged from the last $\sim 8.3 \mathrm{~s}$ ) were fitted with a single-saturating exponential function. The results of both subsets were then analysed by using a simple linear regression: In a plot of known $\alpha$ doses vs. recovered irradiation time the slope of the linear regression was taken as the best estimate for the dose rate of the $\alpha$-source to be calibrated.

It is important to note that the calibration of an $\alpha$ source using the $a$-value system is valid for one specific aliquot size only. 


\section{REFERENCES}

Aitken M, 1985a. Thermoluminescence dating. Academic Press, London.

Aitken M, 1985b. Alpha particle effectiveness: numerical relationship between systems. Ancient TL 3: 22-25.

Aitken M and Bowman S, 1975. Thermoluminescence dating: Assessment of alpha particle contribution. Archaeometry 17: 132-138.

Biswas R, Williams M, Raj R, Juyal N and Singhvi A, 2013. Methodological studies on luminescence dating of volcanic ashes. Quaternary Geochronology 17: 14-25, DOI 10.1016/j.quageo.2013.03.004.

Bösken J, Klasen N, Zeeden C, Obreht I, Marković SB, Hambach U and Lehmkuhl F, 2017. New luminescence-based geochronology framing the last two glacial cycles at the southern limit of European Pleistocene loess in Stalać. Geochronometria 44: 150-161, DOI 10.1515/geochr-2015-0062.

Bösken J, Sümegi P, Zeeden C, Klasen N, Gulyás S and Lehmkuhl F, in press (a). Investigating the last glacial Gravettian site 'Ságvár Lyukas Hill' (Hungary) and its paleoenvironmental and geochronological context using a multi-proxy approach. Palaeogeography, Palaeoclimatology,

Palaeoecology,

DOI 10.1016/j.palaeo.2017.08.010.

Bösken J, Obreht I, Zeeden C, Klasen N, Hambach U, Sümegi P and Lehmkuhl $F$, in press (b). High-resolution proxy data from the MIS3/2 transition recorded in northeastern Hungarian loess. Quaternary International, DOI 10.1016/j.quaint.2017.12.008.

Buylaert J-P, Jain M, Murray AS, Thomsen KJ, Thiel C and Sohbati R, 2012. A robust feldspar luminescence dating method for Middle and Late Pleistocene sediments. Boreas 41: 435-451, DOI 10.1111/j.1502-3885.2012.00248.x.

Colarossi D, Duller GAT and Roberts H, 2018. Exploring the behaviour of luminescence signals from feldspars: Implications for the single aliquot regenerative dose protocol. Radiation Measurements 109: 35-44, DOI 10.1016/j.radmeas.2017.07.005.

Duller GAT, 1992. Luminescence chronology of raised marine terraces, south-west north island, New Zealand. PhD thesis, University of Wales, Abersytwyth.

Duller GAT, 2015. The Analyst software package for luminescence data: overview and recent improvements. Ancient TL 33: 35-42.

Faust D, Yanes Y, Willkommen T, Roettig C, Richter D, Richter D, v. Suchodoletz H and Zöller L, 2015. A contribution to the understanding of late Pleistocene dune sand-paleosol-sequences in Fuerteventura (Canary Islands). Geomorphology 246: 290-304, DOI 10.1016/j.geomorph.2015.06.023.

Franklin AD and Hornyak WF, 1992. Normalization of inclusion size quartz TL data. Ancient TL 10: 1-6.

Jain $\mathrm{M}$ and Ankjærgaard C, 2011. Towards a non-fading signal in feldspar: Insight into charge transport and tunnelling from timeresolved optically stimulated luminescence. Radiation Measurements 46: 292-309, DOI 10.1016/j.radmeas.2010.12.004.

Kenzler M, Tsukamoto S, Meng S, Thiel C, Frechen M and Hüneke H, 2015. Luminescence dating of Weichselian interstadial sediments from the German Baltic Sea coast. Quaternary Geochronology 30: 251-256, DOI 10.1016/j.quageo.2015.05.015.

Kreutzer S, Schmidt C, DeWitt R and Fuchs M, 2014. The $a$-value of polymineral fine grain samples measured with the post-IR IRSL protocol. Radiation Measurements 69: 18-29, DOI 10.1016/j.radmeas.2014.04.027.

Li B and Li SH, 2011. Luminescence dating of K-feldspar from sediments: A protocol without anomalous fading correction. Quaternary Geochronology 6: 468-479, DOI 10.1016/j.quageo.2011.05.001.

Li B, Roberts RG and Jacobs Z, 2013. On the dose dependency of the bleachable and non-bleachable components of IRSL from Kfeldspar: Improved procedures for luminescence dating of Quaternary sediments. Quaternary Geochronology 17: 1-13, DOI 10.1016/j.quageo.2013.03.006.

Mauz B, Packman S and Lang A, 2006. The alpha effectiveness in siltsized quartz: new data obtained by single and multiple aliquot protocols. Ancient TL 24: 47-52.
Murray AS and Mejdahl V, 1999. Comparison of regenerative-dose single-aliquot and multiple-aliquot (SARA) protocols using heated quartz from archaeological sites. Quaternary Science Reviews 18: 223-229, DOI 10.1016/S0277-3791(98)00055-9.

Murray AS and Wintle AG, 2000. Luminescence dating of quartz using an improved single-aliquot regenerative-dose protocol. Radiation Measurements 32: 57-73, DOI 10.1016/S1350-4487(99)00253-X.

Obreht I, Hambach U, Veres D, Zeeden C, Bösken J, Stevens T, Marković SB, Klasen N, Brill D, Burow C and Lehmkuhl F, 2017. Shift of large-scale atmospheric systems over Europe during late MIS 3 and implications for Modern Human dispersal. Scientific Reports 7: 5848, DOI 10.1038/s41598-017-06285-x.

Preusser F, Muru M and Rosentau A, 2014. Comparing different postIR IRSL approaches for the dating of Holocene coastal foredunes from Ruhnu Island, Estonia. Geochronometria 41: 342-351, DOI 10.2478/s13386-013-0169-7.

Rees-Jones J, 1995. Optical dating of young sediments using fine-grain quartz. Ancient TL 13: 9-14.

Reimann T and Tsukamoto S, 2012. Dating the recent past (500 years) by post-IR IRSL feldspar - Examples from the North Sea and Baltic Sea coast. Quaternary Geochronology 10: 180-187, DOI 10.1016/j.quageo.2012.04.011.

Roettig C-B, Kolb T, Wolf D, Baumgart P, Richter C, Schleicher A, Zöller L and Faust D, 2017. Complexity of Quaternary aeolian dynamics (Canary Islands). Palaeogeography, Palaeoclimatology, Palaeoecology 472: 146-162, DOI 10.1016/j.palaeo.2017.01.039.

Rorabacher DB, 1991. Statistical treatment for rejection of deviant values: critical values of Dixon's "Q" parameter and related subrange ratios at the $95 \%$ confidence level. Analytical Chemistry 63: 139-146, DOI 10.1021/ac00002a010.

Schatz A-K, Buylaert J-P, Murray AS, Stevens T and Scholten T, 2012. Establishing a luminescence chronology for a palaeosol-loess profile at Tokaj (Hungary): A comparison of quartz OSL and polymineral IRSL signals. Quaternary Geochronology 10: 68-74, DOI 10.1016/j.quageo.2012.02.018.

Schmidt ED, Tsukamoto S, Frechen M and Murray AS, 2014. Elevated temperature IRSL dating of loess sections in the East Eifel region of Germany. Quaternary International 334-335: 141-154, DOI 10.1016/j.quaint.2014.03.006.

Schmidt C, Schaarschmidt M, Kolb T, Büchel G, Richter D and Zöller L, 2017. Luminescence dating of Late Pleistocene eruptions in the Eifel Volcanic Field, Germany. Journal of Quaternary Science 32: 628-638, DOI 10.1002/jqs.2961.

Schmidt C, Friedrich J, Adamiec G, Chruscinska A, Fasoli M, Kreutzer S, Martini M, Panzeri L, Polymeris GS, Przegietka K, Valla PG, King GE and Sanderson DW, 2018. How reproducible are kinetic parameter constraints of quartz luminescence? An interlaboratory comparison for the $110^{\circ} \mathrm{C}$ TL peak. Radiation Measurements 110: 14-24, DOI 10.1016/j.radmeas.2018.01.002.

Stevens T, Markovic SB, Zech M, Hambach U and Sümegi P, 2011. Dust deposition and climate in the Carpathian Basin over an independently dated last glacial-interglacial cycle. Quaternary Science Reviews 30: 662-681, DOI 10.1016/j.quascirev.2010.12.011.

Thiel C, Buylaert J-P, Murray AS, Terhorst B, Hofer I, Tsukamoto S and Frechen M, 2011. Luminescence dating of the Stratzing loess profile (Austria) - Testing the potential of an elevated temperature post-IR IRSL protocol. Quaternary International 234: 23-31, DOI 10.1016/j.quaint.2010.05.018.

Thomsen K, Murray AS, Jain M and Boetter-Jensen L, 2008. Laboratory fading rates of various luminescence signals from feldspar-rich sediment extracts. Radiation Measurements 43: 1474-1486, DOI 10.1016/j.radmeas.2008.06.002.

Trauerstein M, Lowick SE, Preusser F and Schlunegger F, 2014. Small aliquot and single grain IRSL and post-IR IRSL dating of fluvial and alluvial sediments from the Pativilca valley, Peru. Quaternary Geochronology 22: 163-174, DOI 10.1016/j.quageo.2013.12.004.

Vasiliniuc S, Vandenberghe D, Timar-Gabor A, Panaiotu C, Cosma C and van den Haute P, 2012. Testing the potential of elevated temperature post-IR IRSL signals for dating Romanian loess. Quaternary Geochronology 10: 75-80, DOI 10.1016/j.quageo.2012.02.014. 
Veres D, Cosac M, Schmidt C, Muratoreanu G, Hambach U, Hubay K, Wulf S and Karátson D, 2018. New chronological constraints for Middle Palaeolithic (MIS 6/5-3) cave sequences in Eastern Transylvania, Romania. Quaternary International 485: 103-114, DOI 10.1016/j.quaint.2017.07.015.

Wintle AG, 1973. Anomalous fading of thermoluminescence in mineral samples. Nature 245: 143-144, DOI 10.1038/245143a0.

Zeeden C, Hambach U, Klasen N, Fischer P, Obreht I, Papadopoulou M, Chu W, Schulte P, Bösken J, Schäbitz F, Gavrilov MB, Veres
D, Marković SB, Vött A and Lehmkuhl F, in prep. A Late Quaternary lacustrine record from the south-eastern Carpathian Basin in the context of aeolian sediments.

Zhang J, Tsukamoto S, Nottebaum V, Lehmkuhl F and Frechen M, 2015. $\mathrm{D}_{\mathrm{e}}$ plateau and its implications for post-IR IRSL dating of polymineral fine grains. Quaternary Geochronology 30: 147-153, DOI 10.1016/j.quageo.2015.02.003.

Zimmerman D, 1972. Relative thermoluminescence effects of alpha and beta radiation. Radiation Effects 14: 81-92. 